\title{
SISTEM INFORMASI KULINER KALIMANTAN TENGAH BERBASIS MOBILE MENGGUNAKAN FRAMEWORK CODEIGNEITER
}

\author{
Sutami $^{1}$, Miftahurrizqi ${ }^{2}$, Yong Sutiadi ${ }^{3}$ \\ 1,2 Jurusan Ilmu Komputer, Fakultas Teknik, Universitas Muhammadiyah Palangka Raya, \\ ${ }^{3}$ Mahasiswa Jurusan Ilmu Komputer, Fakultas Teknik, Universitas Muhammadiyah Palangka Raya \\ Jl. RTA. Milono Km.1,5 Palangka Raya, Kalimantan Tengah \\ email: tmy.tamy@gmail.com
}

\begin{abstract}
This research aims to develop a mobile-based information system as a solution of data processing both in terms of storage and reporting that can help as a medium of information services for the wider community who need information about special dishes both dishes made from vegetable ingredients or side dishes in palangkaraya in particular and Central Kalimantan generally become more effective and efficient as well as a solution for the current system, because in carrying out promotional activities they still use promotional media through books, brochures, leaflets or in the form of advertisements in newspapers that are felt to be too much cost incurred for these promotional activities. The specific target resulting from this research is to produce a product in the form of a mobile-based information system to increase public awareness and interest in local specialties, especially in food from Palangka Raya because the delivery of information is very easy and interesting and can foster the interest of people outside or inside to visit and try the cuisine typical city of Palangkaraya.
\end{abstract}

Keywords: Information systems; Culinary; Mobile; CodeIgneiter

\begin{abstract}
Abstrak
Penelitian ini bertujuan untuk pembangunan sistem informasi berbasis mobile sebagai solusi dari pengolahan data baik dari segi penyimpanan maupun pelaporan yang dapat membantu sebagai media layanan informasi bagi masyarakat luas yang membutuhkan informasi mengenai masakan khas baik itu masakan yang terbuat dari bahan sayur atau lauk pauk yang ada di palangkaraya khususnya dan Kalimantan Tengah umumnya menjadi lebih efektif dan efisien serta menjadi solusi bagi sistem yang berjalan saat ini, karena dalam melakukan kegiatan promosi masih menggunakan media promosi melalui buku, brosur, leaflet maupun dalam bentuk iklan di koran yang dirasakan terlalu banyak biaya yang dikeluarkan untuk kegiatan promosi tersebut. Target khusus yang dihasilkan dari penelitian ini yaitu menghasilkan produk berupa sistem informasi berbasis mobile untuk meningkatkan kepedulian dan minat masyarakat terhadap masakan khas daerah khususnya msakan khas palangka raya karena penyampaian informasi sangat mudah dan menarik serta dapat menumbuhkan minat masyarakat luar atau dalam untuk mengunjungi dan mencoba masakan khas kota palangka raya.
\end{abstract}

\section{Kata Kunci: Sistem informasi; Kuliner; Mobile; CodeIgneiter.}

\section{PENDAhuluan}

Kuliner saat ini menjadi sebuah jenis wisata yang sangat banyak dampaknya bagi perkembangan sebuah daerah. Kuliner merupakan sebuah gaya hidup yang tidak dapat dipisahkan. Karena setiap orang memerlukan makanan yang sangat dibutuhkan sehari-hari, mulai dari makanan yang sederhana hingga makanan yang berkelas tinggi dan mewah (Fauzi \& Mulyani, 2017). Salah satu kota yang memiliki keragaman kuliner adalah kota Palangka Raya Kalimantan Tengah.

Selama ini ketika membicarakan tentang makanan khas yang ada di kota Palangka Raya, permasalahan yang dihadapi adalah dalam melakukan kegiatan promosi masih menggunakan media promosi melalui buku, brosur, leaflet maupun dalam bentuk iklan di koran yang dirasakan terlalu banyak biaya yang dikeluarkan untuk kegiatan promosi tersebut sehingga kurangnya efisiensi dalam mencakup 
ketepatan maupun perluasan penyebaran informasi kemudian seringkali keterangan yang bisa di dapat hanyalah terbatas pada nama kuliner nya saja. Sedangkan kejelasan lokasi di mana pusat kuliner tersebut berada serta infomasi-informasi lainnya tidak diinformasikan secara baik. Jika orang mengetahui lokasi dan jenis makanan kuliner lainnya maka dapat dipastikan mereka dapat mencoba hal-hal yag baru dan mengetahui lokasi tempat makannya sehingga secara tidak langsung juga mereka akan berkunjung (Jelantik, 2016).

\section{METODE PENELITIAN}

Tahapan dalam penelitian ini adalah dengan menggunakan model air terjun (Waterfall Model). Waterfall adalah model sekuensial atau alur hidup klasik ( Rosa \& Salahuddin, 2011). Model waterfall (model air terjun) menyediakan pendekatan secara sekuensial atau terurut, yaitu pengerjaan yang dimulai dari satu tahap ke tahap lainnya melalui tahap analisis, desain, pengodean, pengujian dan tahap pendukung (support). Gambar model waterfall

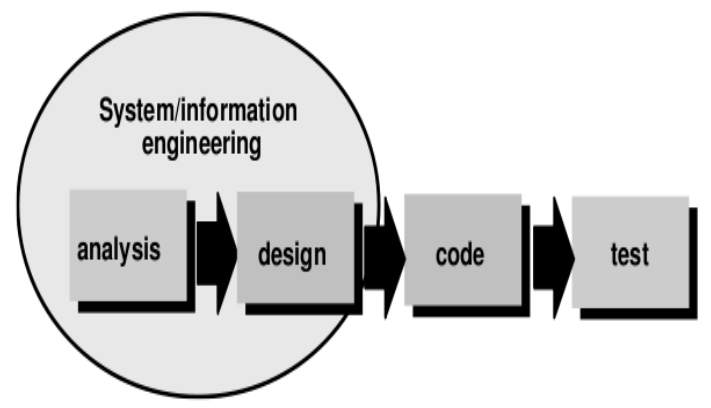

Gambar 1. Waterfall model)

\subsection{Perancangan}

Tahap ini bertujuan untuk mengumpulkan perencanaan-perencanaan yang menguraikan kebutuhan pengguna dan kemudian mentransformasikan ke dalam sebuah deskripsi yang jelas dan lengkap, kemudian akan diaplikasikan ke dalam bentuk perangkat lunak (software).

\subsection{Analisis}

Analisis sistem dapat didefinisikan sebagai tahap penguraian dari suatu system yang dilakukan setelah tahap perencanaan sistem (systems planning) dan sebelum tahap desain sistem (systems design). Istilah analisis sistem sangat tepat tugas utama yang dikerjakan oleh analisi sistem dalam tahap ini yaitu menganalisa sistem untuk menemukan kelemahankelemahannya sehingga dapat diusulkan suatu perbaikannya (Jogiyanto, 2005).

Peneliti mengidentifikasi penyebab dari masalah-masalah yang terjadi yaitu sebagai berikut:

1. Kuliner khas yang ada di kota Palangka Raya kurang begitu terkenal dibandingkan dengan kuliner khas dari daerah-daerah lain di Indonesia. Berdasarkan hasil identifikasi masalah ini disebabkan oleh karena kurangnya promosi mengenai keragaman kuliner khas yang ada di kota Palangka Raya.

2. Banyak website yang membahas informasi kuliner di Indonesia, tetapi untuk informasi kuliner di Kota Palangkaraya masih sangat jarang diulas disebabkan oleh karena kurangnya aplikasi berbasis web yang secara khusus membahas informasi kuliner di Kota Palangka Raya.

\subsection{Desain}

Tahap ini mentranslasi kebutuhan perangkat lunak dari tahap analisis kebutuhan ke representasi desain agar dapat diimplementasikan menjadi program pada tahap selanjutnya. Metode perancangan yang digunakan adalah UML (Unified Modelling Language) untuk menggambarkan use case diagram, activity diagram, dan sequence diagram.

\subsection{Coding}

Implementasi merupakan proses coding pada penelitian berdasarkan kebutuhan perangkat lunak yang telah dianalisa. Setelah unit-unit program telah dibuat dilakukan pengujian pada unit-unit program tersebut. Setelah unit-unit program dilakukan pengujian, selanjutnya program dilakukan pengujian secara menyeluruh, baik perunit program maupun program secara keseluruhan. Dalam hal pembuatan program ini peneliti menggunakan listing program PHP dan MySQL sebagai database.

\subsection{Pengujian}


Aktifitas selanjutnya yang dilakukan setelah melalui tahap Implementasi adalah melakukan pengujian dan evaluasi terhadap sistem yang telah dirancang. Pengujian dan evaluasi ini bertujuan untuk mengetahui apakah desain sistem yang telah dirancang dan dibangun telah sesuai dengan apa yang pengguna inginkan dan apakah sistem telah sesuai dan berjalan dengan baik tanpa ada kesalahan/kegagalan atau tidak berjalan dengan baik. Metode pengujian yang digunakan yaitu Blackbox Testing.

\section{HASIL DAN PEMBAHASAN}

Tahap ini merupakan tahap yang berisi penjelasan tentang manual antar muka sistem dengan tahapan sebagai berikut :

\subsection{Use Case Diagram}

Diagram usecase diperuntukan untuk menggambarkan fungsionalitas sebuah sistem. Sebuah diagram usecase mengidentifikasi aktor yang terlibat dalam kegiatan yang dapat dilakukan terhadap aplikasi. Dalam hal ini meliputi user dan system.

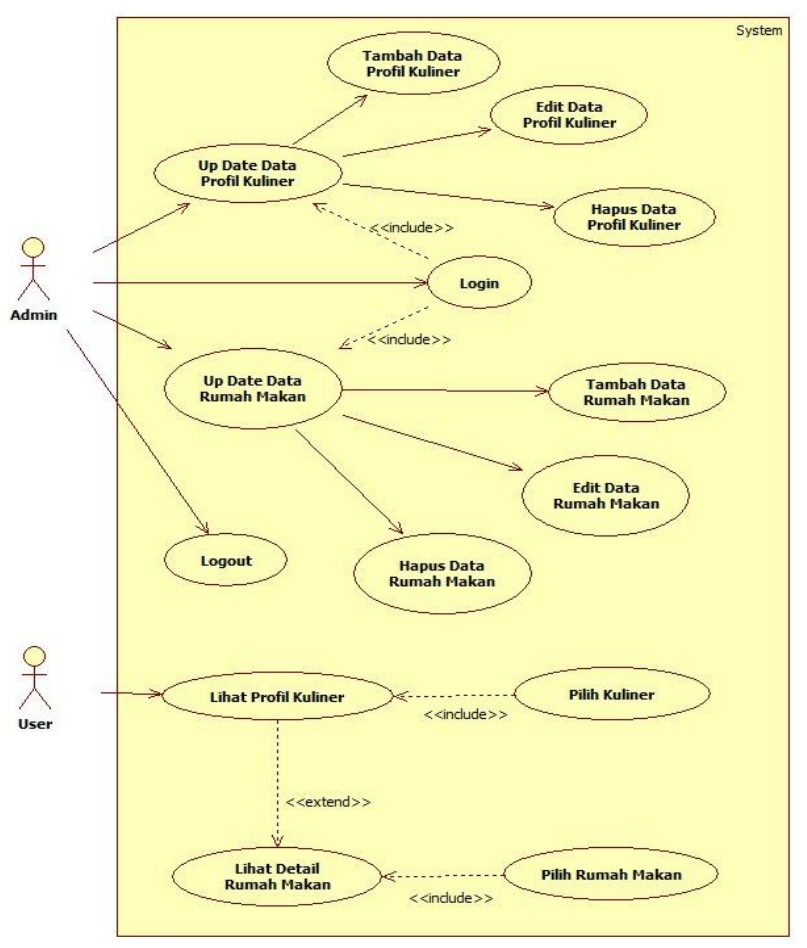

Gambar 2. Use Case Diagram

\subsection{Antar muka sistem}

Pada antar muka sistem ini akan dijelaskan bagaimana cara user dan admin menggunakan aplikasi ini, mulai dari pertama kali menjalankan aplikasi, login, dan kemudian cara menggunakan menu yang ada didalamnya yang dapat dilihat pada gambar 3.

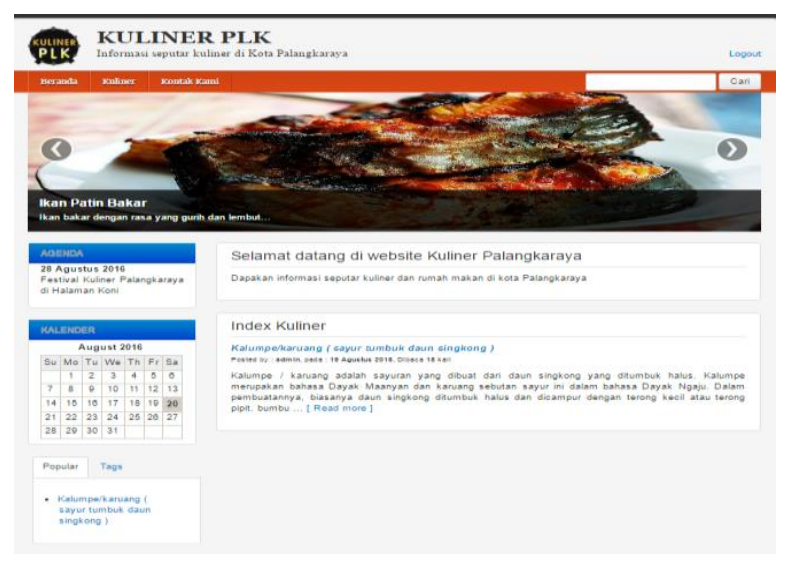

Gambar 3. Antar muka sistem

\subsubsection{Antar muka User}

Pada halaman utama ini user/pengunjung dapat dapat memilih dan mengakses pilihan menu-menu yang telah disediakan pada website makanan khas palangka raya yang terdiri dari menu beranda, makanan khas dan kontak kami,. Kemudian pada halaman utama ini juga bisa dilakukan pencarian data makanan dan agenda kegiatan.

\subsubsection{Antar muka Administrator}

- Halaman Login

Halaman login merupakan halaman yang digunakan sebagai pintu gerbang bagi seorang administrator website sebelum masuk ke sistem untuk mengelola seluruh data-data pada sistem. Tampilan login dapat dilihat pada gambar 4.

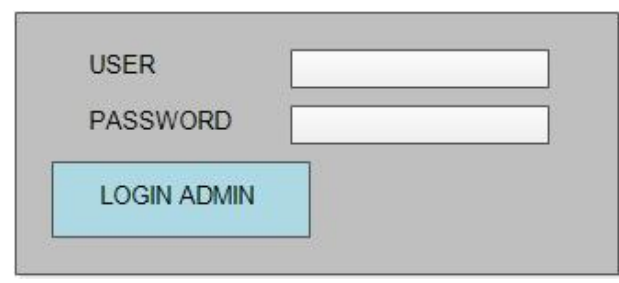

Gambar 4. Halaman Login

- Halaman Utama Administrator

Halaman ini merupakan tampilan halaman utama administrator yang digunakan sebagai halaman untuk mengelola data-data dan informasi pada sistem yang nantinya akan ditampilkan pada halaman utama user pada gambar 5. 


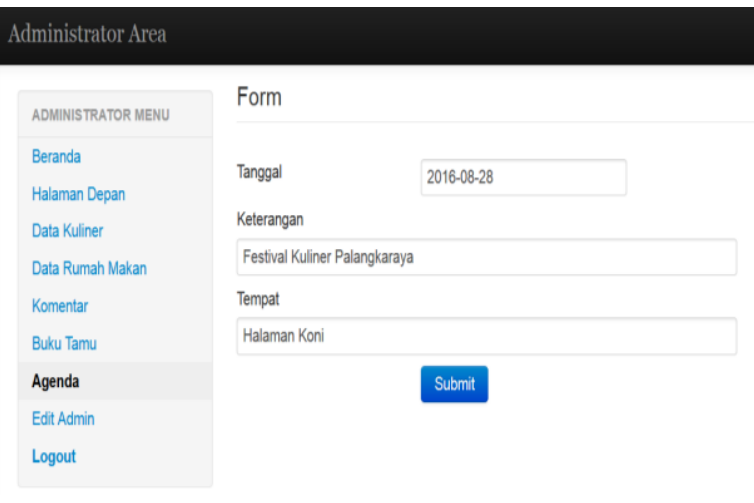

Gambar 5. Halaman utama administrator

- Halaman Administrator Data Kuliner

Halaman dibawah ini adalah halaman administartor untuk penginputan data-data kuliner baik nama kuliner, foto kuliner, profil kuliner, kategori kuliner, dan lokasi ketersediaan kuliner. Untuk tampilan desain dapat dilihat pada gambar 6.

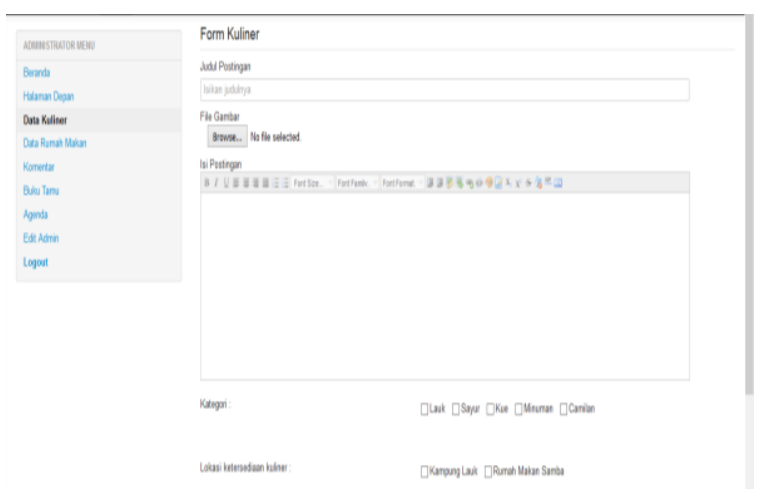

Gambar 6. Halaman Administrator data Kuliner

- Halaman Administrator data rumah makan

Halaman ini dapat menambah, edit dan hapus data rumah makan meliputi nama rumah makan, foto rumah makan, alamat rumah makan dan waktu operasional rumah makan pada gambar 7 .

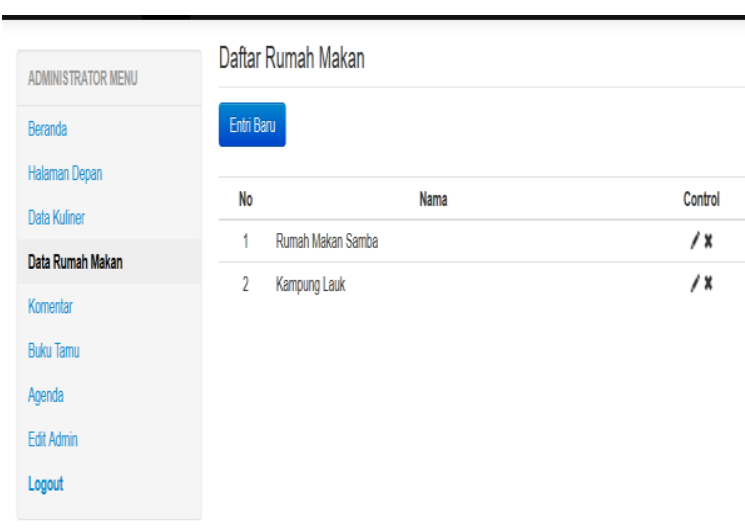

Gambar 7. Halaman data rumah makan

- Halaman Administrator komentar

Jika suatu data kuliner telah dikomentari oleh pengunjung, untuk melihat komentar tersebut klik tombol lihat komentar. Selanjutnya halaman akan dialihkan ke menu komentar namun komentar yang ditampilkan hanya komentar yang ada di judul kuliner yang dipilih sebelumnya.

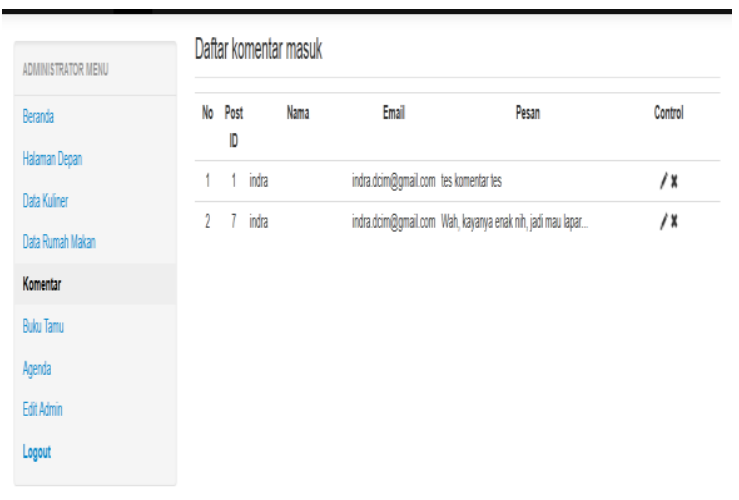

Gambar 8. Halaman Adminstrator komentar

- Halaman administrator buku tamu

Pada menu buku tamu terdapat list pesan dari pengunjung dari halaman publik. Terdapat kolom aksi yang berisi tombol hapus seperti pada gambar 9 .

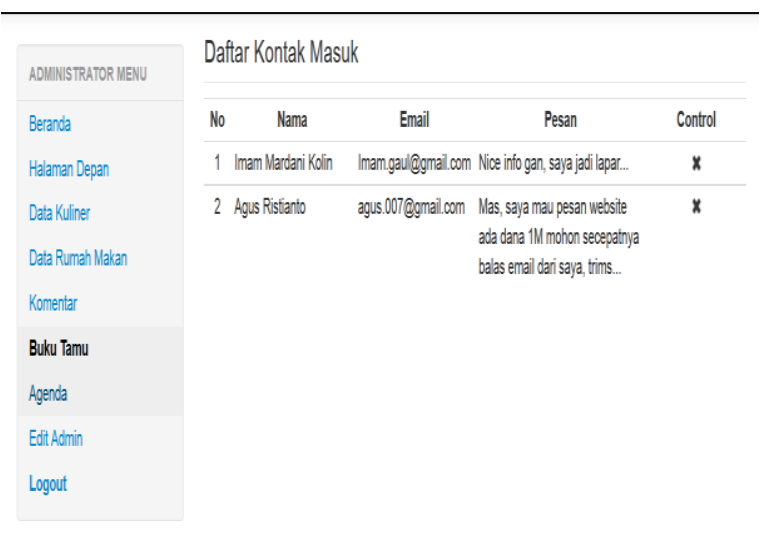

Gambar 9. Halaman data buku tamu

- Halaman Administrator Agenda

Pada menu agenda terdapat list agenda yang akan ditampilkan di sidebar halaman publik. Terdapat beberapa kolom aksi yang berisi tombol edit, dan hapus seperti pada gambar 10. 


$$
\begin{array}{r|c}
\text { Jurnal Sains Komputer dan Teknologi Informasi } & \text { Page } \\
\text { e-issn: 2655-7460. Volume 2 No.1, November 2019 } & 40-45
\end{array}
$$

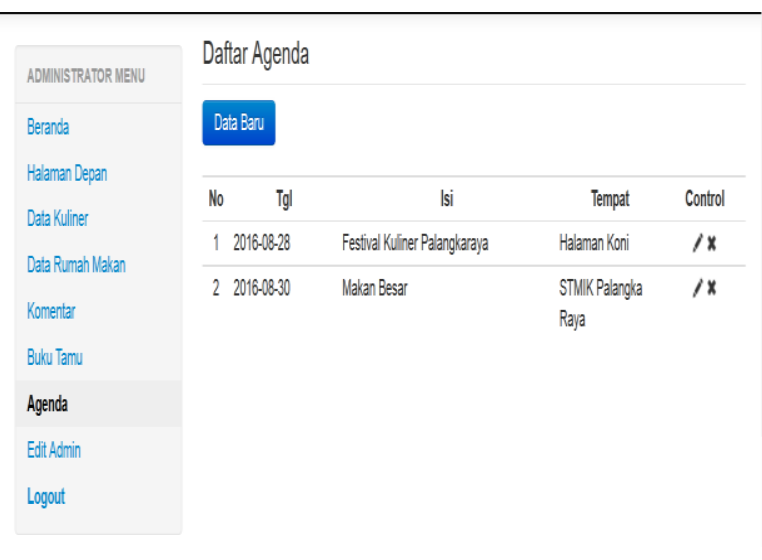

Gambar 10. Halaman Agenda

- Halaman Edit Administrator

Pada menu edit admin form untuk mengganti username atau password admin seperti pada gambar 11.

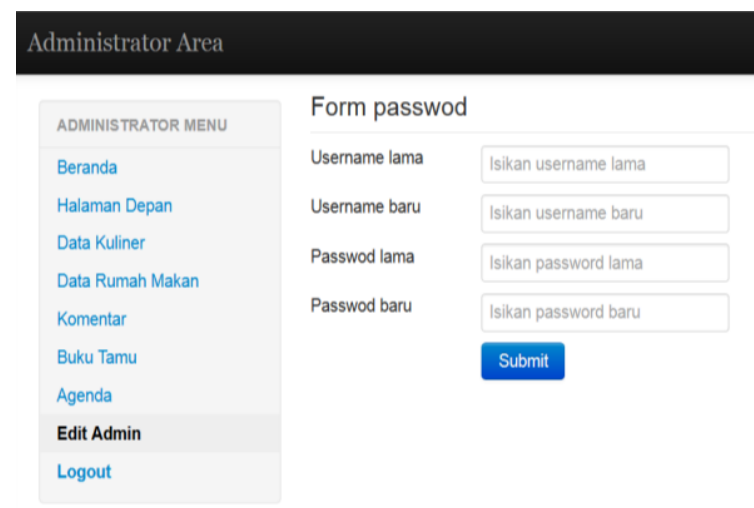

Gambar 11. Halaman Edit Administrator

\subsubsection{Pengujian Sistem}

Pada Pengujian sistem ini dilakukan dengan menggunakan pengujian blackbox testing terhadap user dan admin sebagai berikut:

- Pengujian untuk User

\begin{tabular}{|c|c|c|c|}
\hline No & Kelas Uji & Butir Uji & Harapan \\
\hline \multirow[t]{2}{*}{1.} & Pengujian & Proses Lihat & Data Kuliner \\
\hline & $\begin{array}{l}\text { Lihat Data } \\
\text { Kuliner }\end{array}$ & Data Kuliner & $\begin{array}{l}\text { dapat } \\
\text { ditampilkan }\end{array}$ \\
\hline \multirow[t]{2}{*}{2.} & Pengujian & Proses Lihat & Data Kontak \\
\hline & Lihat Kontak & Data Kontak & $\begin{array}{l}\text { dapat } \\
\text { ditampilkan }\end{array}$ \\
\hline 3. & $\begin{array}{l}\text { Pengujian } \\
\text { Lihat kategori }\end{array}$ & $\begin{array}{l}\text { Proses lihat } \\
\text { data kategori }\end{array}$ & $\begin{array}{l}\text { Data kategori } \\
\text { dapat } \\
\text { ditampilkan }\end{array}$ \\
\hline 4. & $\begin{array}{l}\text { Pengujian } \\
\text { Lihat agenda }\end{array}$ & $\begin{array}{l}\text { Proses } \\
\text { agenda }\end{array}$ & $\begin{array}{l}\text { Agenda dapat } \\
\text { ditampilkan }\end{array}$ \\
\hline
\end{tabular}

Tabel 5. Rencana Pengujian Member
- Pengujian Untuk Administrator

\begin{tabular}{|c|c|c|c|}
\hline No & Kelas Uji & Butir Uji & Harapan \\
\hline 1. & $\begin{array}{l}\text { Pengujian } \\
\text { login } \\
\text { administrator }\end{array}$ & $\begin{array}{lr}\text { Login } & \text { untuk } \\
\text { masuk } & \text { ke } \\
\text { halaman } & \\
\text { administrator }\end{array}$ & $\begin{array}{c}\text { Text input } \\
\text { username/password } \\
\text { salahakan muncul } \\
\text { pesan }\end{array}$ \\
\hline 2. & $\begin{array}{l}\text { Pengujian } \\
\text { untuk } \\
\text { pengisian } \\
\text { pengelolaan } \\
\text { data halaman } \\
\text { depan }\end{array}$ & $\begin{array}{l}\text { Proses edit data } \\
\text { halaman depan }\end{array}$ & $\begin{array}{c}\text { Data halaman depan } \\
\text { dapat diedit }\end{array}$ \\
\hline 3. & $\begin{array}{l}\text { Pengujian } \\
\text { untuk } \\
\text { pengisian } \\
\text { pengelolaan } \\
\text { data kuliner }\end{array}$ & $\begin{array}{l}\text { Proses tambah, } \\
\text { edit dan hapus } \\
\text { data untuk data } \\
\text { kuliner }\end{array}$ & $\begin{array}{c}\text { Data kuliner dapat } \\
\text { ditambah, dihapus, } \\
\text { dan diedit }\end{array}$ \\
\hline 4. & $\begin{array}{l}\text { Pengujian } \\
\text { untuk } \\
\text { pengisian } \\
\text { pengelolaan } \\
\text { data rumah } \\
\text { makan }\end{array}$ & $\begin{array}{l}\text { Proses tambah, } \\
\text { edit dan hapus } \\
\text { data untuk data } \\
\text { rumah makan }\end{array}$ & $\begin{array}{l}\text { Data rumah makan } \\
\text { dapat ditambah, } \\
\text { dihapus, dan diedit }\end{array}$ \\
\hline 5. & $\begin{array}{l}\text { Pengujian } \\
\text { untuk } \\
\text { pengisian } \\
\text { pengelolaan } \\
\text { data komentar }\end{array}$ & $\begin{array}{l}\text { Proses tambah, } \\
\text { edit dan hapus } \\
\text { data untuk data } \\
\text { komentar }\end{array}$ & $\begin{array}{c}\text { Data komentar } \\
\text { makan dapat } \\
\text { ditaambah, dihapus, } \\
\text { dan diedit }\end{array}$ \\
\hline 6. & $\begin{array}{l}\text { Pengujian } \\
\text { untuk } \\
\text { pengisian } \\
\text { pengelolaan } \\
\text { data tamu }\end{array}$ & $\begin{array}{l}\text { Pengujian untuk } \\
\text { penghapusan } \\
\text { pengelolaan } \\
\text { data tamu }\end{array}$ & $\begin{array}{c}\text { Data tamu dapat } \\
\text { dihapus }\end{array}$ \\
\hline 7. & $\begin{array}{l}\text { Pengujian } \\
\text { untuk } \\
\text { pengisian } \\
\text { pengelolaan } \\
\text { data agenda }\end{array}$ & $\begin{array}{l}\text { Proses tambah, } \\
\text { edit dan hapus } \\
\text { data untuk data } \\
\text { agenda }\end{array}$ & $\begin{array}{l}\text { Data rumah agenda } \\
\text { dapat ditambah, } \\
\text { dihapus, dan diedit }\end{array}$ \\
\hline 8. & $\begin{array}{l}\text { Pengujian } \\
\text { untuk } \\
\text { pengisian } \\
\text { pengelolaan } \\
\text { data admin }\end{array}$ & $\begin{array}{l}\text { Proses } \\
\text { untuk } \\
\text { admin }\end{array}$ & $\begin{array}{c}\text { Data admin dapat } \\
\text { diedit }\end{array}$ \\
\hline
\end{tabular}

Tabel 6. Rencana Pengujian Administrator

\section{PENUTUP}

\section{Kesimpulan}

Aplikasi yang dibangun menyesuaikan alur dan kebutuhan pengguna yang digambarkan pada diagram dan perancangan antarmuka menggunakan software yang mendukung seperti Balsamiq Mockups dapat membantu dan memudahkan dalam membangun aplikasi karena gambaran rancangan yang cukup jelas. Hasil pengujian dengan blackbox testing menunjukkan bahwa adanya kesesuaian antara pengujian dengan hasil yang diharapkan. Hal ini menunjukkan bahwa sistem dapat diimplementasikan. 


\section{Saran}

Diharapkan nantinya sistem dapat diujikan untuk mengetahui kelayakan bagian fitur dan fungsionalitasnya terhadap interface sistem, pengujian dapat dilakukan dengan metode lainnya seperti white-box dan mengharapakan agar pengembang selanjutnya dapat mengembangkan menggunakan framework yang lain .

\section{REFERENSI}

Andi, (2013). Pengembangan Aplikasi Web Mobile. Setia Kawan Perss, Jakarta .

A.S, Rosa dan Salahuddin, M (2011). Rekayasa Perangkat Lunak (Terstruktur dan berorientasi objek). Modula. Bandung.

Basuki Pribadi A (2014). Proyek Membangun Website Berbasis PHP dengan Codeignite. Lokomedia, Yogyakarta.

Fauzi, A., Mulyani (2017). Perancangan Sistem Informasi Kuliner DiBrother Caffe Berbasis Web. Jurnal Algoritma STT-Garut Vol.14. No.2. ISSN: 23027339.

Jogiyanto (2012). Sistem Informasi dan Tekniksal Pengembangan Perangkat Lunak. Informatika. Bandung.

Jelantik Suryaningrat (2016). Perancangan Sistem Informasi Wisata Kuliner Berbasis Web Dengan Menggunakan Ajax. Jurnal Sistem Dan Informatika Vol.10, No.2, Mei.

Kurniawan, P (2016) "Perancangan Sistem Informasi Wisata Kuliner DiKota Salatiga Menggunakan Aplikasi Hybrid Berbasis Android. Skripsi, Prodi Sistem Informasi. Universitas Kristen Satya Wacana Salatiga.

Marliyati, Sri Anna, Sulaeman., Achmad (2013). Anwar Faisal. Pengolahan Pangan Tingkat Rumah Tangga. IP., Bogor. 82-83.

Sutanta, Edhy (2011). Sistem Jaringan Komputer Untuk Pemula, Setia Kawan Perss. Jakarta. 